\title{
Espiões, Mentiras e Livros. Literatura de viagens e (des)informação nos anos 30 ou: a vida e os escritos do Dr. Manfred Zapp
}

\author{
Fernando Clara \\ Universidade Nova de Lisboa - ILCML
}

Resumo: 0 nome do Dr. Manfred Zapp ficou sobretudo conhecido internacionalmente por ter sido acusado de espionagem e expulso dos Estados Unidos em 1941, quando era director da agência de notícias nazi Transocean News Service em Nova Iorque. Antes de 1941 Zapp estivera em Portugal, onde desempenhara funções em instituições muito próximas da legação alemã em Lisboa; depois de 1945 há provas de que continuava ligado às autoridades portuguesas prestando serviços de informação e de "relações públicas" ao regime de Salazar. Partindo da vida e escritos desta figura cosmopolita e viajada o ensaio procura reflectir sobre a centralidade da política para o mundo do século XX e sobre as continuidades que o labiríntico percurso bio-bibliográfico de Zapp deixa entrever.

Palavras-chave: Manfred Zapp, Espionagem, Propaganda, II Guerra Mundial, Relações Luso-alemãs

\begin{abstract}
The name of Dr. Manfred Zapp became internationally known for having been accused of espionage and expelled from the United States in 1941, when he was director of the Nazi news agency Transocean News Service in New York. Before 1941 Zapp had been in Portugal, where he held positions at German institutions closely related to the German legation in Lisbon; after 1945 there is evidence that he was still connected to the Portuguese authorities providing information services and "public relations" to the Salazar regime. Drawing on the life and writings of this cosmopolitan and well-travelled character the essay seeks to reflect on the centrality of politics to the twentieth century world and on the continuities that the labyrinthine biobibliographical path of Zapp unveils.
\end{abstract}

Keywords: Manfred Zapp, Espionage, Propaganda, II World War, German-Portuguese relations 
O mundo europeu dos anos 30 do século XX é um mundo hiper-politizado que tem no seu centro a figura (ideal e abstracta) do Estado. Mussolini tinha-o dito de uma forma muito clara em 28 de Outubro de 1925, num discurso proferido em Milão (Mussolini 1956: 425): "tutto nello Stato, niente al di fuori dello Stato, nulla contro lo Stato" ["tudo no Estado, nada fora do Estado, nada contra o Estado"]. E mesmo antes da subida ao poder de Hitler na Alemanha, o jurista Carl Schmitt já sublinhava que este "novo tempo" se caracterizava, mais precisamente, pelo primado do político, uma vez que "Der Begriff des Staates setzt den Begriff des Politischen voraus" ["o conceito de Estado pressupõe o conceito de político"] (Schmitt 1932: 7). O conceito de político, omnipresente e omnipotente na sociedade da época, assume portanto um papel central no mundo dos anos 30 e, durante cerca de duas décadas, sobrepõe-se de uma forma parasitária a toda a vida das nações não deixando nenhuma área incólume à sua influência (da ciência à estética, sem esquecer naturalmente a ética).

Uma reflexão interessada na (história da) cultura deste período não pode, por isso, evitar as questões de ordem política, tanto mais que se trata de um período profundamente marcado por uma funcionalização política da própria cultura e das culturas nacionais. Considerem-se a este título as transformações paradigmáticas que dois produtos culturais a viagem e a literatura de viagens - conhecem na época: o ambiente político-cultural em que ambas necessariamente se vêem obrigadas a integrar torna-as particularmente sensíveis, uma vez que se situam, seja por tradição, seja pelas características inerentes à própria actividade viática, num plano que transcende - e cujo objectivo é na verdade transcender - as fronteiras erigidas pelos nacionalismos. Ora conhecer e dar a conhecer o outro significa em primeiro lugar trabalhar numa área a que os Estados e as políticas da época atribuem especial importância: a área onde se joga a construção das identidades nacionais. Daí que a viagem se torne numa actividade rigidamente controlada pelos Estados e a literatura de viagens do período se transforme num produto cultural especialmente sensível à influência do poder político por via das questões identitárias que ali se colocam. E valerá a pena acrescentar que algumas das questões que os relatos de viagem da época colocam não são só incómodas, como também exigem respostas que nem sempre são 
simples. Vejam-se, por exemplo, as publicações de Annemarie Schwarzenbach sobre o Portugal de Salazar (cf. Vilas-Boas 2001 e Schwarzenbach 2004), nas quais se torna evidente uma nítida simpatia por um país que tem um "governo de professores" e por um regime que se diz ser uma "ditadura de intelectuais" (apud Vilas-Boas 2001: 156), uma visão reconhecidamente estranha, ou pelo menos inesperada, por parte de uma autora cujas publicações assumem predominantemente perspectivas anti-fascistas e, sobretudo, antinazis (cf. Vilas-Boas 2001: 157 ss.). Uma boa parte da estranheza e do incómodo provocados por estas observações rapidamente se dissipa, no entanto, quando estas imagens do Portugal de Salazar são consideradas à luz de um contexto histórico mais alargado que tenha em linha de conta, não apenas o "espírito humanista" (ibidem: 158) da autora, mas também o quadro de relacionamento luso-suíço em que elas se inscrevem, assim como o espaço (nacional) em que a autora e o seu público se integram (cf. Vilas-Boas 2011). E é justamente nesse sentido que importa recordar aqui o nome de Gonzague Reynold, escritor suíço que em 1937 havia ganho a primeira edição do Prémio Camões, atribuído pelo Secretariado de Propaganda Nacional português à melhor obra estrangeira sobre Portugal, com um livro apologético do regime salazarista (Reynold 1936), e que em Maio de 1939 deixava um veemente apelo à consciência nacional do povo suíço ("Schweizer, seid Schweizer!" [Suíços, sede Suíços!]) onde não hesitava em recorrer às palavras de Salazar para explicar a lógica subjacente ao exercício da autoridade (Reynold 1939: 78):

Der Sinn der Verantwortung entfaltet sich nur da, wo die Autorität ist. Salazar, der Begründer des neuen Portugal, sagt: "Die Autorität ist ein Recht, aber auch eine Pflicht; eine Pflicht, die sich selbst verleugnet, wenn sie nicht ausgeübt wird, ein Recht, das seine festeste Grundlage im Wohle Aller hat. Die Autorität ist eine herrliche Gabe der Vorsehung, denn weder das soziale Leben noch die Knltur wären möglich ohne die Autorität".

[O sentido da responsabilidade só se desenvolve plenamente onde há autoridade. Salazar, o fundador do novo Portugal, diz: "A autoridade é um direito mas também é um dever, um dever que se nega a si próprio se se não exerce, direito que tem no bem comum o seu melhor fundamento. A autoridade é um alto dom da providência, porque sem ela nem seria possível a vida social nem a cultura"] ${ }^{1}$ 
Num ambiente deste género, globalmente propício à afirmação da autoridade e ao reconhecimento de regimes autoritários, a visão que Annemarie Schwarzenbach tem do Portugal de Salazar perde muito da sua estranheza inicial. As questões anteriormente tidas por inesperadas diluem-se e deixam de o ser porque encontram um enquadramento e uma explicação. E vale a pena acrescentar que todo este processo de resgate do ambiente em que os textos se inscrevem tem sobretudo um mérito que aqui importa destacar: o mérito de nos fazer recordar que não é possível compreender a literatura ou a arte - e muito em particular a literatura e a arte deste período específico - fora do seu contexto históricopolítico.

Ao transbordar para fora das suas fronteiras habituais o conceito de político, no entanto, também se transforma, torna-se permeável a outros estilos e tradições discursivas, adquirindo novas qualidades que lhe asseguram a tão desejada indistinção entre o seu domínio original de actuação e outros espaços que lhe seriam em princípio estranhos (como os da ciência ou da estética). Dito de outro modo: a politização da estética tem como contrapartida a estetitização da política. Assim, não surpreende que a história (política) ultrapasse, por vezes com uma exuberância notável, a própria ficção (literária). A época aqui em análise é, de resto, pródiga em figuras históricas de uma ficcionalidade que, em alguns casos, se diria próxima do picaresco (em boa verdade, próxima do pior picaresco). Líderes carismáticos, militares prepotentes, divas deslumbrantes, polícias corruptos, detectives discretos ou, enfim, espiões e mentiras não fazem apenas parte do modo como hoje se tende a imaginar aquele período histórico, todas estas figuras são de facto parte integrante do quotidiano da época, como fica registado no cartaz norte-americano a seguir reproduzido (Fig. 1). 


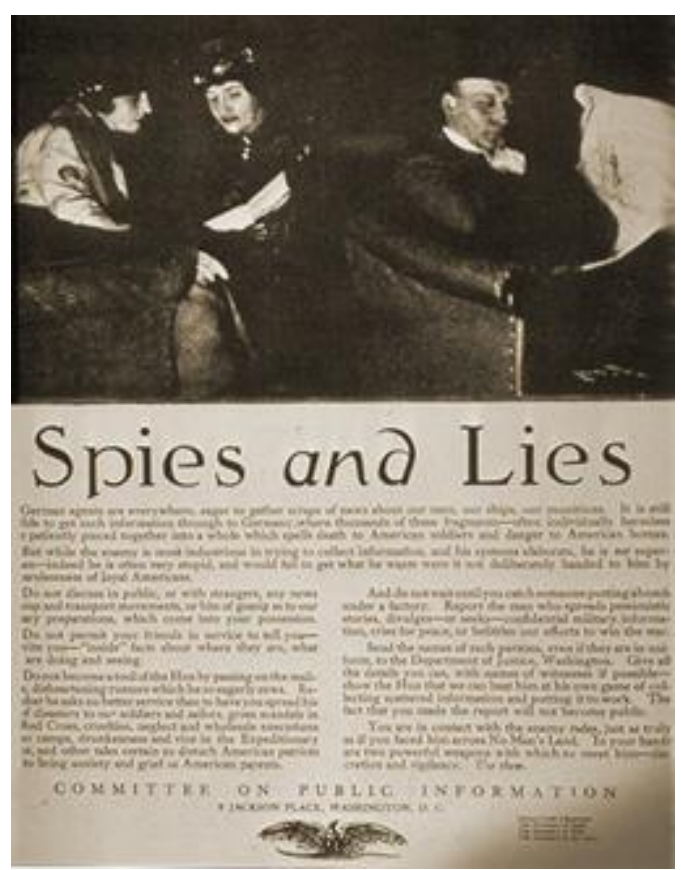

Fig. 1

(fonte: http://www.bible-researcher.com/dresden/spiesandlies.jpg)

A mancha gráfica da imagem, que não prescinde ainda de um texto muito longo e explicativo, trai a época da sua produção (1917), anterior portanto a uma fase fortemente apostada na "educação visual" (Neurath 1937) e na propaganda visualmente apelativa como foi a década de 30, mas ao mesmo tempo o cartaz e a sua temática anunciam já o mundo da II Guerra Mundial, um mundo que teve - e tem tido - particular sucesso no âmbito da ficção contemporânea: de Casablanca a Lisboa e da literatura ao cinema, parece ter sido a exuberância da história da época a tomar conta da sua própria ficção.

Para o modo como hoje se imagina este período contribuíram decisivamente indivíduos que é preciso resgatar ao terreno pantanoso, obscuro e, tantas vezes, ambíguo da história do período, como é o caso do "Dr. Manfred Zapp", chefe da agência de notícias alemã Transocean News Service em Washington, e principal protagonista de um caso de espionagem que o atirou para as primeiras páginas dos jornais norte-americanos (e europeus) em 1940 e 1941 num processo que culminaria com a sua expulsão dos Estados Unidos. ${ }^{2}$ 
$\mathrm{Na}$ origem deste episódio está uma iniciativa do Congresso Norte-Americano que decidiu encarregar Martin Dies de investigar as actividades anti-americanas ("unamerican") de sabotagem e propaganda levadas a cabo naquele país por grupos políticos específicos, fundamentalmente comunistas e nazis. $\mathrm{Na}$ sequência das conclusões preliminares deste relatório elaborado pela equipa de seis investigadores liderados pelo congressista Dies, ${ }^{3}$ Zapp e uma extensa lista de diplomatas alemães e italianos nos Estados Unidos são expulsos do país em Julho de 1941 e os respectivos consulados encerrados (cf. DoSB 1941). De um ponto de vista formal, o motivo do repatriamento de Zapp apresenta um argumento relativamente frágil e algo paradoxal: o facto de não se ter registado, aquando da sua chegada à América do Norte, como agente de uma potência estrangeira, conforme estipulava o "Foreign Agent Registration Act" (Annual Report 1942: 117-118). Dito de outra forma: Zapp era expulso como "espião" porque não se registou como "espião".

É evidente que a guerra estava perto. Importa aliás referir que Berlim já havia respondido ao facto de Zapp ter sido constituído arguido (na fase inicial do processo) com a prisão de Richard C. Hottelet, correspondente da United Press em Berlim (cf. FRUS 1941, II: 597 ss., Oechsner 1969 e Ritchie 2005: 98-99), de modo que todo este episódio tem naturalmente de ser considerado num ambiente de progressivo agravamento das relações entre os EUA e os países do Eixo que culminaria, em Dezembro de 1941, na declaração de guerra aos Estados Unidos por parte da Alemanha.

Da vida e das obras dos espiões sabe-se habitualmente pouco e Manfred Zapp, "the Casanova head of the Nazi handout agency Transocean News Service", como é apresentado num livro publicado já depois do final da guerra (Ambruster 1947: 292), não constitui a este título excepção. 0 que há de curioso neste caso é que uma boa parte do pouco que se sabe tem justamente origem no volume que o relatório de Dies lhe dedica (Dies 1940). Depois de uma breve passagem pela África do Sul, Zapp ruma aos EUA, no final de 1938, com a incumbência de montar nas Américas filiais de uma agência de notícias alemã. Tratase da já mencionada Transocean News Service, uma agência de notícias fundada em 1913 "with the explicit purpose of spreading German news overseas" (Evans 2010: 210) e que, depois da tomada do poder Hitler, caiu sob a alçada nacional-socialista tornando-se numa 
espécie de agência-sombra (alegadamente de direito privado e portanto menos limitada e menos controlável nos seus modos de actuar) da agência de notícias oficial da Alemanha, o Deutsches Nachrichtenbüro. ${ }^{4}$

A parte do relatório especificamente dedicada a Zapp e à Transocean apresenta 238 provas, maioritariamente constituídas pela correspondência de Zapp com diplomatas alemães. De entre essas provas destaca-se desde logo uma breve encenação biográfica do próprio Zapp que, nas circunstâncias actuais, parece ser um dos poucos documentos sobre as actividades desta figura menos conhecida e com uma vida que parece confirmar quase todos os estereótipos habitualmente associados à imagem do espião durante o período nazi (Dies 1940: 970 e 1116-1117, onde se encontra o fac-simile do original alemão).

Manfred Zapp, whose Rhineland accent is true to his home city of Duesseldorf has gone about the world a great deal. Other European countries, with the exception of Scandinavia and the Balkan states, are all well known to him. One year in Paris, two years in Rome, and frequent visits to London brought him together with leading men of France, Italy, and England. The Balkan states, Holland, Belgium, Spain, and Portugal were repeatedly visited by him. He was engaged for half a year in Moscow and repeatedly revisited it in the service of the large German papers such as the Frankfurter Zeitung, Berliner Boersenzeitung, and large provincial newspaper companies. He lived almost a year in Japan. During the Manchurian War, he was in Manchuria and in China. Before the outbreak of the Abyssinian War, he visited the Italian colonies on the invitation of the Italian Government. For the Scherl Publishing Company he travelled through South and Central Africa, as well as the former German Colony of East Africa. He was in Ireland for the Berliner Boersenzeitung and a group of large provincial newspapers. At the beginning of the Spanish Campaign, he was correspondent of the Berliner Boersenzeitung and the Koelnischen Zeitung in Portugal. He gathered together his studies of Portugal in a book, "Portugal, an Authoritarian State". He has given lectures in German and foreign secondary institutions of learning.

His present job in New York is to represent the interest of the Transocean News Service in the United States and Canada.

É claro que o tom descontraído e amigável desta encenação biográfica, próprio de um comunicado à imprensa ou de uma apresentação social ou comercial (que é de facto o que esta nota biográfica é), não proporciona muita informação factual. Em todo o caso vale 
a pena registar Düsseldorf como a cidade onde nasceu, uma vida até ali preenchida por inúmeras viagens aparentemente ligadas profissionalmente à imprensa, e um livro publicado, sobre Portugal, cujo título se enquadra perfeitamente na época. A partir destas informações, e com base nelas, é possível entretanto reunir hoje uma série de dados biobibliográficos sobre Zapp, os quais confirmam uma certa aura cosmopolita patente na encenação biográfica acima transcrita, mas que ao mesmo tempo permitem descortinar os interesses do seu autor e a sua verdadeira área de expertise: o nacional-socialismo.

Zapp nasceu em Düsseldorf em 1903 numa família de industriais do aço da Renânia. Doutorou-se na Universidade de Leipzig, em 1929, com uma tese sobre as relações francoalemãs na última década do século XIX (Zapp 1929) e, nos anos seguintes ao doutoramento, publica uma série de artigos nos Preussische Jahrbücher que permitem identificar com muita nitidez os seus interesses e o seu pensamento. Com efeito, a par de uma primeira reflexão comparada sobre o fascismo e o absolutismo (Zapp 1930), os artigos que Zapp vai deixando na revista prussiana parecem estar todos ligados às várias viagens que empreendeu e têm todos no seu centro o nacional-socialismo, ou melhor: a expansão do movimento national-socialista em países como o Japão (1933a), a Espanha (1933b), a Turquia (1933c) ou a Irlanda (1934). Nos anos seguintes, já com Hitler no poder, o ritmo de publicações mantém-se, mas o espaço geopolítico de actuação de Zapp significativamente alarga-se e inclui agora a Índia (Zapp 1935a), a Rússia (1935b) e a África do Sul (1936 e 1938).

No centro destes textos, todos eles decorrentes de viagens que o seu autor efectivamente terá realizado, não está apenas a política, mas sim uma ideologia política. 0 tradicional carácter formativo da viagem (e da literatura de viagens) dera portanto lugar a um discurso informativo, a estética da escrita a uma retórica política.

Note-se que esta curiosa lista das publicações de Zapp está muito provavelmente longe de estar completa, uma vez que foi já possível identificar textos do autor sobre Portugal num jornal grego ligado ao regime de Metaxas (cf. Ploumidis 2014: 78 e Bogiatzis 2016: 115, 119). Um sinal claro de que os fascismos, contrariamente ao que a historiografia desta área muitas vezes dá a entender, estão profundamente apostados na sua 
internationalização e na construção de redes transnacionais. Em todo o caso, o que é sem dúvida interessante é que na encenação biográfica acima referida Zapp menciona apenas uma publicação sua: o livro Portugal als autoritärer Staat, publicado em 1937, em Berlim, na editora Deutscher Verlag für Politik und Wirtschaft, uma editora próxima dos meios conservadores e nacional-socialistas e que tinha estado particularmente activa na denúncia das "injustiças" a que o povo alemão fora sujeito após o tratado de Versalhes.

O livro é composto por 10 capítulos que haviam sido anteriormente parcialmente publicados nas páginas dos jornais Kölnische Zeitung e Berliner Börsenzeitung e resulta da estadia de Zapp em Lisboa, que deverá ter ocorrido entre os anos de 1936 e 1938 onde desempenhou cargos junto da Legação Alemã em Lisboa e do Grémio Luso-Alemão (mais tarde Centro Luso-Alemão de Intercâmbio Cultural), uma importante instituição de propaganda alemã em Lisboa que fazia a ponte directa entre a sociedade civil portuguesa e a Alemanha nazi. O Portugal de Zapp é digno de nota neste contexto específico do relacionamento luso-alemão na medida em que é um livro sem paralelo no quadro das publicações alemãs existentes sobre o Portugal da época: ao contrário do que então era prática (diplomática) corrente nestas publicações, Zapp não se coíbe de estruturar toda a sua argumentação e narrativa histórica em torno da teoria da raça, o principal "eixo teórico do fascismo alemão" (Reich 1933: 115), de modo que o resultado é uma "versão ariana", radical, distorcida e caricata da história de Portugal que dispensa quaisquer comentários (Zapp 1937: 12).

300 Jahre lang blieb Portugal ein Reich unter germanischer Führung, teils suebischer, teils westgotischer Könige. Gerade der starke Einschlag der Sueben ist es, der dem portugiesischen Volkscharakter eine Sonderart verlieh. Ihr germanisches Blut muß sich bis in die großen Zeiten des Spätmittelalters und der frühen Neuzeit erhalten haben, denn ein Teil der bedeutenden Männer Portugals wird als hochgewachsen, blond und blauäugig beschrieben. So wird z.B der portugiesische Dichter Luis Vaz de Camões der im 16. Jahrhundert gelebt und geschaffen hat, geschildert mit fast safrangelbem Haar, blauen Augen und heller Hautfarbe. Sein Vorname Vaz, das alte Vazzo, jetzt Waz, ist echt germanisch.

[Durante 300 anos Portugal esteve sob o domínio germânico de reis, em parte suevos e em parte visigodos. Foi justamente da forte marca deixada pelos Suevos que o carácter do povo português 
recebeu o seu traço excepcional. 0 sangue germânico deve ter-se mantido até aos grandiosos tempos do final da Idade Média e do início do Renascimento, pois uma parte dos mais importantes portugueses são descritos como sendo altos, louros e tendo olhos azuis. 0 poeta português Luís Vaz de Camões, por exemplo, que viveu e escreveu no século XVI, é descrito como tendo cabelos quase cor de açafrão, olhos azuis e uma pele clara. O seu nome Vaz, o antigo Vazzo que agora é Waz, é autenticamente germânico]. ${ }^{5}$

Após a expulsão dos Estados Unidos Zapp regressa à Europa no navio militar norteamericano USS West Point que atraca no porto de Lisboa, a cidade para onde as autoridades alemãs tinham também enviado o (já atrás mencionado) jornalista norte-americano Richard C. Hottelet que havia sido preso em Berlim pela Gestapo como retaliação pela acusação feita a Zapp. De acordo com o repórter da United Press, recentemente falecido, foi em Lisboa que se procedeu à troca dos dois homens (cf. Ross 2014).

No regresso à Alemanha Zapp percorre diversos países dando conferências (nomeadamente na França ocupada) que versam, desta vez, temas relacionados com a América e os Americanos; em 1942 publica o seu maior sucesso editorial, Zwischen Wallstreet und Kapitol. Politiker und Politik in USA, um livro que conhece pelo menos duas edições; em Berlim acaba por ser nomeado chefe da secção para os assuntos americanos do ministério dos negócios estrangeiros do Reich (cf. FRUS 1945, III: 938) depois de ter passado pela embaixada alemã em Ancara (Schrafstetter 2015: 119). Finalmente, em meados de Abril de 1945 é feito prisioneiro pela 89ạ divisão de infantaria do exército norteamericano (Finley 1945) e sujeito ao processo de desnazificação.

Mas a história de Zapp não termina aqui. A partir de inícios de 1950 está de volta à sua actividade de publicista. A temática dos seus textos conhece contudo, naturalmente, uma notória (e compreensível) inflexão. Colabora em revistas como Die Deutsche Zukunft, Die Plattform (cf. Schrafstetter 2015: 119), Der Spiegel e numa série de outras publicações, quase todas elas dedicadas ao tecido industrial alemão no pós-guerra (Herchenröder et al. 1953 ou Reichelt 1956). Em 1958 é um dos fundadores do Clube Alemão de Relações Públicas (Heinrich 1958), que mais tarde se torna numa associação profissional do sector, e em 1961 prefacia a tradução alemã do relatório McGraw-Hill sobre "Public Relations"6 
(Zapp 1961). Será certamente por isso que Zapp é considerado hoje uma das referências históricas das relações públicas na Alemanha do pós-guerra.

Sinuosos, labirínticos e ambíguos são pois os caminhos que vão da informação à espionagem ou da propaganda às relações públicas, sobretudo quando esses caminhos são (profissionalmente) percorridos no século XX (cf. Tworek 2015 ou Heinelt 2003). Considerem-se, a título de exemplo, as alterações que o campo semântico da palavra "propaganda" conhece durante este período e que reflectem de uma forma particularmente nítida o modo como o discurso político de então se apropria de um termo inicialmente oriundo da esfera religiosa, que começara entretanto a ser usado com alguma frequência nos meios comerciais (no sentido de "publicidade") e que, subitamente deslocado para a esfera política, se vê radicalmente transformado (cf. Kennedy 1943, entre diversos outros autores da época). Destas alterações, e das batalhas terminológicas que a afirmação de uma ideologia sempre implica - uma ideologia é em primeiro lugar e sobretudo uma terminologia -, dá bem conta um discurso de Goebbels significativamente pronunciado por ocasião de um congresso de agentes publicitários ("Reklamekongreß") que teve lugar em Viena em Junho de 1938. Depois de tecer uma série de observações sobre o modo como o regime nazi contribuiu para denunciar "as tristes caricaturas" em que muitas palavras, expressões ou instituições da época se haviam tornado ("Democracia", "Aristocracia", "Sociedade das Nações" ou "direito à auto-determinação dos povos") Goebbels, que é apresentado como "o mestre da palavra", detém-se no termo "propaganda" para referir que tal como havia sucedido com as outras palavras (DNB 1938):

So sei auch einst ein Hohngelächter durch die ganze Welt gegangen, als Deutschland dem Wort "Propaganda" einen neuen und positiven Wert unterlegt habe, als bald nach der Gründung des Dritten Reiches das erste und damals einzige Propagandaministerium der Welt errichtet wurde. Man habe es damals nicht verstanden, wie man das Wort "Propaganda" in Beziehung bringen konnte zu einer staatlichen Einrichtung.

[Também outrora soou pelo mundo uma gargalhada de escárnio, quando a Alemanha deu à palavra "propaganda" um valor novo e positivo, quando logo após o estabelecimento do Terceiro Reich foi criado o primeiro e até então único Ministério da Propaganda. Na altura não se entendia como era 
possível relacionar a palavra "propaganda" com uma instituição do Estado].

Contudo, estas transformações não podem nem devem ignorar a ambiguidade decorrente das contiguidades semânticas evidenciadas por palavras como "informação" "espionagem", "propaganda” ou "relações públicas”, nem as continuidades que também lhes estão subjacentes e que estranhamente se prolongam até à actualidade: certamente por ironia do destino, um dos trabalhos mais recentes onde o nome de Zapp é mencionado como referência histórica importante da área das relações públicas é da Universidade de São Paulo e tem origem no "Departamento de Relações Públicas, Propaganda [!] e Turismo" (Mateus 2012).

Igualmente curioso, em todo o caso, é que esta indisfarçada e ambígua continuidade é extensiva, também e de novo, ao relacionamento do publicista alemão com as autoridades portuguesas do pós-guerra. De facto, Manfred Zapp é um dos nomes constantes da "Relação de algumas individualidades às quais foram fornecidos elementos de estudo para a elaboração de livros, artigos, conferências, etc. sobre assuntos portugueses”, uma lista extensa "de expedição de propaganda por personalidades" relativa ao ano de 1952 elaborada pelo antigo Secretariado de Propaganda Nacional, que entretanto fora também já re-baptizado de Secretariado Nacional da Informação, Cultura Popular e Turismo (Cotrim 2010: 98).

E a ligação de Zapp a Portugal não se fica ainda por aqui, já que em 1964 Manfred Zapp terá sido um dos fundadores, juntamente com outras personalidades entre as quais se encontra o então embaixador de Portugal na República Federal da Alemanha (Manuel Homem de Mello), da Associação Luso-Alemã,7 e em 1971 uma das firmas patrocinadoras da comemoração do centenário do Clube Alemão em Lisboa tem a designação comercial de "Manfred Zapp Lda." (cf. Deutscher Verein 1971). Tratava-se da filial de uma firma alemã sediada em Düsseldorf que actuava na área das relações públicas (Mateus 2012: 44) e que tinha sido incumbida de representar os interesses de Portugal na Alemanha ocidental. A firma mantinha por isso estreitos contactos com as autoridades portuguesas (cf. Lopes 2011: 109 e Duarte de Jesus 2015: 52) que se materializaram também em publicações, 
como a brochura sobre investimentos em Portugal (Zapp 1968) ou a versão alemã de um volume sobre Cabora Bassa editado pelo Secretariado de Nacional Informação (Zapp 1971).

É sabido que o percurso labiríntico de Zapp é semelhante a muitos outros percursos individuais (e até institucionais) do pós-guerra alemão (cf. Heinelt 2003). São percursos que importa questionar, como aqui se procurou fazer, sobretudo quando se inscrevem no quadro do relacionamento do espaço de língua alemã com aqueles países para os quais o final da II Guerra Mundial não constituiu um momento de ruptura com o passado, como foi, entre outros, o caso de Portugal ou Espanha. São histórias que merecem ser revistas e revisitadas, talvez não tanto para, com base nelas, formular juízos (quaisquer que eles sejam), mas sim, mais, por motivos que se prendem com a preservação da memória e com a necessidade de ter uma compreensão mais completa e abrangente da época. Com efeito, as continuidades de que estas histórias dão testemunho parecem permitir uma compreensão não amputada do longo século XX, que dizer uma compreensão já liberta dos valores da própria época e das visões bipolares que a formaram e que nela se formaram (primeiro até 1945 e depois até 1989). Permitem revisitar o modo como uma filosofia política do Estado tomou parasitariamente conta de tradições estéticas, epistemológicas e literárias com alguns séculos e também perceber como essa filosofia política pôde subsistir em territórios que lhe eram próximos ou contíguos, mesmo depois de ter desaparecido. Permitem desfazer alguns mitos sobre o isolamento (político, social etc.) dos regimes nacionalistas autoritários de então e perceber que a rede internacional de comunicação que os sustentava era afinal suficientemente vasta e fiável para lhes sobreviver. Permitem, enfim, perceber as rupturas que assaltaram o mundo da época, mas também as continuidades que lhe deram forma, proporcionando assim um olhar mais completo sobre o modo como foi sendo construído e desconstruído esse labirinto de discursos polifónicos que é o nosso imaginário do século XX. 


\section{Bibliografia}

Ambruster, Howard Watson (1947), Treason's peace: German dyes \& American dupes. New York: The Beechhurst Press.

Annual Report (1942) Annual report of the Attorney General of the United States for the Fiscal Year ended June 30 1941, Washington, D.C.: United States Government Printing Office. Bell, Leland V. (1970), "The Failure of Nazism in America: The German American Bund, 1936-1941", Political Science Quarterly 85(4): 585-599.

Bogiatzis, Vassilios A. (2016), “The Longing for a 'Conservative Revolution': German Influences over the Greek Inter-war Politicization of Technology and Science", in Fernando Clara/Cláudia Ninhos (Eds.), Nazi Germany and Southern Europe, 1933-45: Science, Culture and Politics, New York: Palgrave Macmillan: 105-119.

Carlson, John Roy (1943), Under Cover. My four years in the Nazi underworld of America - the Amazing revelation of how Axis agents and our enemies within are now plotting to destroy the United States, New York: E.P. Dutton.

Clara, Fernando (2014), "A «questão da raça», as redes internacionais do Instituto IberoAmericano de Berlim e as suas relações com Portugal (1933-1945)", in Fernando Clara/Cláudia Ninhos C (Eds.), A Angústia da Influência. Política, Cultura e Ciência nas relações da Alemanha com a Europa do Sul, 1933-1945, Frankfurt am Main: Peter Lang: 119155.

Cotrim, João Pedro Caeiro da Silva Bernardo (2010), Tradutores e Propagandistas. Da tradução como ferramenta de propaganda do Estado Novo no estrangeiro e da indústria que se desenvolveu em torno desta no Secretariado da Propaganda Nacional/Secretariado Nacional de Informação. Diss. de Mestrado, Coimbra: Universidade de Coimbra.

Deutscher Verein (1971), Festschrift zur Hundertjahresfeier des Deutschen Vereins in Lissabon: 1870-1970. Lisboa. 
Diamond, Sander A. (1975), "Zur Typologie der amerikadeutschen NS-Bewegung", Vierteljahrshefte für Zeitgeschichte 23(3): 271-296.

Dies, Martin (1939), Investigation of Un-American Activities and Propaganda. Report of the Special Committee on Un-American Activities pursuant to H. Res. 282 (75th Congress). Washington, D.C.: United States Government Printing Office.

-- (1940), Investigation of Un-American Propaganda Activities in the U.S.: Appendix, Part 2: A Preliminary Digest and Report on the Un-American Activities of Various Nazi Organizations and Individuals in the United States, Including Diplomatic and Consular Agents of the German Government. Washington, D.C.: United States Government Printing Office.

DNB (1938), "Dr. Goebbels auf dem Reklamekongreß in Wien”, Deutsches Nachrichtenbüro 5. Jg., Sonnabend, 11. Juni, Nr. 950.

DoSB (1941), "Closing of German and Italian Consulates in the United States", Department of State Bulletin V(108): 59-65.

Duarte de Jesus, José Manuel (2015), Espionagem e Contraespionagem em Portugal. Vicissitudes e Mistérios. Lisboa: Leya.

Evans, Heidi J. (2010), "'The path to freedom'? Transocean and German wireless telegraphy, 1914-1922", Historical Social Research 35(1): 209-233.

Finley, Thomas D. (1945), Rolling ahead! The story of the 89th infantry division. [Paris]: [P. Dupont].

Freifeld, Sidney A. (1942), "Nazi Press Agentry and the American Press", The Public Opinion Quarterly 6(2): 221-235.

Freitas, Joana Gaspar de (2003), "Gonzague de Reynold e Oliveira Salazar: 25 anos de correspondência", Clio. Revista do Centro de História da Universidade de Lisboa 8: 117-193.

FRUS (1861-1958/1960), Foreign relations of the United States. Diplomatic Papers. Washington: United States Government Printing Office.

Heinelt, Peer (2003), 'PR-Päpste': Die kontinuierlichen Karrieren von Carl Hundhausen, Albert 
Oeckl und Franz Ronneberger. Berlin: Dietz.

Heinrich, Karl (1958), "Es geht nicht ohne Public Relations", Die Zeit 13, 27. März 1958, Hamburg (on-line: http://www.zeit.de/1958/13/es-geht-nicht-ohne-public-relations; consultado em 25 de Janeiro de 2016).

Herchenröder, Karl Heinrich/Schäfer, Johann/Zapp, Manfred (1953), Die Nachfolger der Ruhrkonzerne: Die 'Neuordnung der Montanindustrie'. Düsseldorf: Econ-Verl.

Kennedy, Foster (1943), “De Propaganda Fide”, Canadian Medical Association Journal 49(3): 218-223.

Lavine, Harold/Wechsler, James (1940), War Propaganda and the United States. New Haven: Yale University Press.

Liebert, Herman (1941a), "International Communications", The Public Opinion Quarterly 5(1): 114-119.

-- (1941b), “International Communications”, The Public Opinion Quarterly 5(2): 295-298.

Lopes, Rui Miguel Ponte Vieira (2011), Between Cold War and colonial wars: the making of West German policy towards the Portuguese dictatorship, 1968-1974. Tese de Doutoramento, London: The London School of Economics and Political Science.

Mateus, Anabela Ferreira Félix (2012), Estudo comparado sobre o 'estado da arte' da Comunicação Organizacional e das Relações Públicas entre Portugal e o Brasil. Uma primeira abordagem. Relatório de Pesquisa de Pós-doutorado em Ciências da Comunicação, Comunicação Organizacional e Relações Públicas, São Paulo: Universidade de São Paulo (on-line:http://www3.eca.usp.br/sites/default/files/webform/projetos/posdoc/AFFM.pdf; consultado em 25 de Janeiro de 2016).

Mussolini, Benito (1956), "Per la Medaglia dei Benemeriti del Comune di Milano", in Edoardo Susmel (Ed.), Opera omnia. 21. Dal delitto Matteotti all'attentato Zaniboni (14 giugno 1924-4 novembre 1925), Firenze, LaFenice: 422-427. 
Neurath, Otto (1937), "Visual Education", Survey Graphic. Magazine of Social Interpretation XXVI(1): 25-28.

Oechsner, Frederick Cable (1969), “A Modern Tale of Two Cities”, The International Lawyer 4(1): 97-106.

Ploumidis, Spyridon (2014), "Corporatist Ideas in Inter-War Greece: From Theory to Practice (1922-1940)", European History Quarterly 44(1): 55-79.

Reichelt, Werner O. (1956), Das Erbe der IG-Farben. Düsseldorf: Econ-Verl.

Reich, Wilhelm (1933), Massenpsychologie des Faschismus; zur Sexualökonomie, der politischen Reaktion und zur proletarischen Sexualpolitik. Kopenhagen: Verlag für Sexualpolitik.

Reilly, Michael F./Slocum, William J. (1947), Reilly of the White House. New York: Simon and Schuster.

Reynold, Gonzague de (1936), Portugal. Paris: Editions Spes.

-- (1939), "Schweizer, seid Schweizer!", Schweizer Monatshefte: Zeitschrift für Politik, Wirtschaft, Kultur 19(2): 73-82.

Riess, Curt (1941), Total espionage. New York: G.P. Putnam's Sons.

-- (1944), The Nazis go underground. Garden City, New York: Doubleday, Doran and Co.

Ritchie, Donald A. (2005), Reporting from Washington: The History of the Washington Press Corps. Oxford; New York: Oxford University Press.

Ross, Jeannette (2014), “Veteran newsman Richard C. Hottelet of Wilton dies at 97", Wilton Bulletin, 17th December (on-line: http://www.wiltonbulletin.com/33288/veterannewsman-richard-c-hottelet-of-wilton-dies-at-97/; consultado em 25 de Janeiro de 2016). Schmitt, Carl (1932), Der Begriff des Politischen. München: Duncker \& Humblot.

Schrafstetter, Susanna (2015), "Siegfried Zoglmann, His Circle of Writers, and the Naumann Affair: A Nazi Propaganda Operation in Postwar Germany", in David A. Messenger/Katrin 
Paehler (Eds.), A Nazi past: recasting German identity in postwar Europe, Lexington, KY: University Press of Kentucky: 113-138.

Schwarzenbach, Annemarie (2004), Annemarie Schwarzenbach em Portugal (1941, 1942): textos de Annemarie Schwarzenbach sobre Portugal. Ed. Gonçalo Vilas-Boas, trad. de Maria Antónia Amarante. Coimbra: Centro Interuniversitário de Estudos Germanísticos.

Sieburg, Friedrich (1937), Neues Portugal. Bildnis eines alten Landes. Frankfurt am Main: Societäts-verlag.

Steiner, H. Arthur (1935), "Fascism in America?", The American Political Science Review 29(5): 821-830.

Strempel, Heribert von (1946), "Confessions of a German Propagandist", The Public Opinion Quarterly 10(2): 216-233.

Trefousse, Hans Louis (1951), Germany and American neutrality, 1939-1941. New York: Bookman Associates.

Tworek, Heidi J.S. (2015), "Political and Economic News in the Age of Multinationals", Business History Review 89(03): 447-474.

Vilas-Boas, Gonçalo (2001), '“Céu aberto sobre Lisboa': a escritora Annemarie Schwarzenbach em Portugal 1941 e 1942", Revista da Faculdade de Letras: Estudos 1: 149160 .

-- (2011), "Olhares suíços sobre Portugal: de Reynold a Loetscher", Cadernos de Literatura Comparada 24/25: 137-165.

Wingender, Maxime (2010), Le Comité Dies (special House Committee on un-American Activities) et son regard sur les mouvements d'extrême droite Américains, 1938-1944. Diss. de Mestrado, Montreal: Université du Québec.

Zapp, Manfred (1929), Deutsch-französische Annäherungsversuche und ihr Scheitern in den Jahren 1890-1898. Diss. de Doutoramento (Leipzig). Weida im Thüringen: Thomas \& Hubert. 
Espiões, Mentiras e Livros. Literatura de viagens e (des)informação nos anos 30 ou: a vida e os escritos do Dr.

-- (1930), “Faschismus und Absolutismus”, Preussische Jahrbücher 222: 293-306.

-- (1933a), "Die nationalsozialistische Bewegung in Japan", Preussische Jahrbücher 232: 193-199.

-- (1933b), “Spanien und der Nationalsozialismus”, Preussische Jahrbücher 234: 148-153.

-- (1933c), “Türkischer Nationalsozialismus”, Preussische Jahrbücher 233: 105-112.

-- (1934), “Irlands Unrast”, Preussische Jahrbücher 236: 148-162.

-- (1935a), “Die britisch-indische Eisenindustrie”, Weltwirtschaftliches Archiv 41: 132-142.

-- (1935b), Die sowjetrussische Sphinx. Düsseldorf: Girardet.

-- (1936), “Das Deutschtum in Südafrika”, Europäische Revue 12(12b): 1084-1091.

-- (1937), Portugal als autoritärer Staat. Berlin: Deutscher Verlag für Politik und Wirtschaft.

-- (1938), Die Struktur der südafrikanischen Presse sowie der Presse in dem Mandatsgebiet von Südwestafrika und in Portugiesisch-Ostafrika. S.l., s.n.

-- (1942), Zwischen Wallstreet und Kapitol. Politiker und Politik in USA. Berlin: Wilhelm Limpert-Verlag.

-- (1961), Public Relations heute. Bad Godesberg: ESTO Public Relations- und Verlagsgesellschaft Lothar von Balluseck.

-- (1968), Wirtschaftspartner Portugal: ein Leitfaden für Investitionen. Düsseldorf: Manfred Zapp.

-- (1971), Cabora Bassa: Daten, Fakten und Meinungen über einen Staudamm in Mozambique. Lissabon: Zapp-PR/Staatssekretariat für Information und Tourismus (SEIT). 
Fernando Clara é Professor Auxiliar do Departamento Línguas, Culturas e Literaturas Modernas da Faculdade de Ciências Sociais e Humanas da Universidade Nova de Lisboa. As suas principais áreas de docência e investigação compreendem os Estudos Alemães, os Estudos Culturais e as Relações Luso-Alemãs. Publicações recentes: A Angústia da Influência. Política, Cultura e Ciência nas relações da Alemanha com a Europa do Sul, 1933 1945. Frankfurt am Main: Peter Lang 2014 (em colaboração com Cláudia Ninhos), Várias Viagens. Estudos oferecidos a Alfred Opitz. V. N. Famalicão: Húmus 2011 (em colaboração com Manuela Ribeiro Sanches e Mário Matos), Rahmenwechsel Kulturwissenschaften. Würzburg: Königshausen \& Neumann 2010 (em colaboração com Peter Hanenberg, Isabel Capeloa Gil e Filomena Viana Guarda), Outros Horizontes. Encontros luso-alemães em contextos coloniais. Lisboa: Colibri 2009 e Mundos de Palavras. Viagem, História, Ciência, Literatura: Portugal no espaço de Língua Alemã (1770-1810). Frankfurt am Main: Peter Lang 2007.

\section{NOTAS}

${ }^{1}$ Sobre o relacionamento de Reynold e Salazar veja-se Freitas (2003). Salvo indicação em contrário as traduções portuguesas dos textos citados são da minha responsabilidade.

2 Da passagem de Zapp pela América, assim como de todo este processo, há inúmeros testemunhos na literatura ocasional e memorialística da época, uma literatura que não tem merecido ainda a atenção que provavelmente mereceria por parte da investigação (cf. Ambruster 1947, Carlson 1943, Freifeld 1942, Lavine/Wechsler 1940, Liebert 1941a e 1941b, Reilly/Slocum 1947, Riess 1941 e 1944, Steiner 1935 ou Strempel 1946); sobre o relacionamento entre os EUA e a Alemanha e a penetração nazi na América cf. Bell (1970), Diamond (1975) ou Trefousse (1951) entre muito outros.

3 Detalhes sobre este "comité Dies", cujas actividades se estendem de 1938 a 1944, tendo produzido mais de 10.000 páginas distribuídas por 17 volumes, estão disponíveis em Wingender (2010). 
${ }^{4}$ A apresentação da empresa que consta como prova № 2 do relatório de Dies é ligeira mas significativamente diferente: "Transocean G.m.b.H., which was founded in the Spring of 1914 by a group of Hamburg business men, exporters, and bankers is still today a private undertaking, which is similar to the United Press or the International News Service here in America and delivers news, within a smaller compass, however, to newspapers throughout the world" (Dies 1940: 969); importa referir que a agência havia já estado representada nos Estados Unidos no início dos anos 30 (Diamond 1975: 278), pelo que a nomeação de Zapp para o cargo terá sido determinada pela nova dinâmica geopolítica do regime nazi; sobre a história da Transocean e em particular sobre a sua expansão nas Américas vejam-se o já citado Evans (2010) e Tworek (2015: 8 ss.).

5 O carácter inédito (e caricaturalmente radical) desta visão de Zapp fica bem patente quando ela é confrontada com outros textos alemães da época sobre Portugal, como por exemplo o livro de Friedrich Sieburg, Neues Portugal. Bildnis eines alten Landes, publicado também no mesmo ano de 1937 sob os auspícios do Secretariado de Propaganda Nacional (Sieburg 1937); sobre o modo diferenciado como a "questão da raça" era normalmente tratada - quer dizer: diplomaticamente silenciada - no contexto luso-alemão da época cf. Clara (2014: 139-142).

${ }^{6}$ Vale a pena notar que tanto a versão alemã deste relatório como o Clube Alemão fundado em 1958 adoptam de facto a expressão anglo-americana "Public Relations", obliterando assim da (sua própria) memória a genealogia política recente, incómoda mas incontornável, destas áreas de trabalho.

${ }^{7}$ Assim o informa pelo menos o próprio site da Associação (http://www.dpg-report.de/wir.htm; consultado em 25 de Janeiro de 2016). 